\title{
High Pressure Sintering of WC-10Co Doped with Rare-Earth Elements
}

\author{
C.M.F.G. Marques, G.S. Bobrovnitchii and J.N.F Holanda \\ Northern Fluminense State University - UENF, Laboratory of Advanced Materials - \\ LAMAV, Campos dos Goytacazes, RJ, \\ Brazil
}

\section{Introduction}

The cemented carbides are usually known as the hard metals. They are typically two phase composite materials, in which a hard refractory carbide phase is bonded by an iron-group metal, usually metallic cobalt (Thümmler e Oberacker, 1993). This is due to its ability to wetting the carbide particles, which allows the agglomeration of particles, giving the material toughness. The tungsten carbide (WC) due to its metallic nature presents an excellent thermal conductivity. Thus, the cemented carbide is a typical example of composite material.

The properties of cemented carbides are related to a combination of the properties of individual constituents. Thus, the attractive properties of such materials are related to the carbide hardness combined with toughness of the binder metal. When compared to other systems, WC-Co exhibits the best combination of mechanical strength, wear resistance and good toughness (Schwarzkopf and Kieffer, 1986). Considering this fact, WC-Co is an unique system in this field of materials.

The demands of the industrial and economical development worldwide at the beginning of the twentieth century resulted in the development of the cemented carbide (Williams, 1998). Since that time the cemented carbide is a class of materials of great technological importance, whose main applications are in machining operations and as tooling for metal forming or cutting. In addition, the cemented carbides can also be applied in drawing dies, drawing, stamping and metal forming, mining and wear-resistant pieces. Thus, these materials are applied in those activities that require high abrasion resistance, hardness and impact resistance, such as heavy machining and drilling.

The properties of the cemented carbides can be modified from changes in the proportions of the materials used in its manufacture. There are several cemented carbide compositions in which the cobalt phase can vary from 3 to $30 \mathrm{wt} . \%$. However, the most usual composition and of high interest in this chapter is that based on $90 \mathrm{wt}$ \% tungsten carbide (WC) and 10 wt.\% cobalt (Co) (German, 1994).

The cemented carbide is conventionally produced by powder metallurgy processing via liquid phase sintering. The elemental powders are comminuted, mixed, compacted, and 
sintered under various conditions. The processes commonly used are pressing/sintering, hot pressing, and sinter/hot isostatic pressing (HIP) (North et al., 1991; White, 1998). Recently, an unusual process for the production of cemented carbide using a high pressure technique has been investigated (Rodrigues et al., 2006). On the other hand, the effect of the rare-earth elements addition on the sintering behavior of cemented carbide has also been investigated. In particular, the beneficial effects of the rare-earth elements on the mechanical properties, microstructure and cutting performance have been extensively investigated (Li et al., 1986; Yao et al., 1987; Liang et al., 1989; Shan, 1990; Luo, 1991; Liu et al., 1992; Chenguang, 1992; Pan, 1993; Yang et al., 1993; Deng, 1993; Li et al, 1993; He et al., 1994; Li et al, 1994; Yan et al., 1995; Cheng and Yu, 1995; Yuan et al., 1995; Li, 1996; He, 1996; Ji et al., 1996; Xu et al., 2001; Gomes, 2004). However, the production of cemented carbide doped with rare-earth elements using a high pressure technique is still to be investigated.

This chapter focuses on the possibility of production of WC-10wt.\%Co doped with rareearth elements under high pressure and high temperature (HPHT) conditions. Emphasis is given on the effects of the rare-earth additions on the densification behavior and physical and mechanical properties of the end product.

\section{Preparation and testing of the cemented carbide}

\subsection{Materials and mixture preparation}

The materials used in powder form were: tungsten carbide (WC), cobalt (Co), cerium oxide $\left(\mathrm{CeO}_{2}\right)$, lanthanum oxide $\left(\mathrm{La}_{2} \mathrm{O}_{3}\right)$, calcite $\left(\mathrm{CaCO}_{3}\right)$, and graphite.

The tungsten carbide powder of high purity used was provided by Wolfram Bergbau-Und$\mathrm{GmbH}$, whose main characteristics are presented in Table 1. The cobalt powder of high purity was provided by Vetec Química Fina, whose grain size is $<400$ mesh. The rare-earth oxides (> $99 \%$ ) were provided by Vetec Química Fina. The calcite and graphite were used in assembling the reactive cell in the high-pressure experiments. The graphite powder of high purity was provided by Nacional Grafite.

\begin{tabular}{|l|c|}
\hline \multicolumn{1}{|c|}{ Characteristic } & Range \\
\hline Total C, wt. $\%$ & 6.15 \\
\hline Free C, wt. $\%$ & 0.04 \\
\hline Density, $\mathrm{g} / \mathrm{cm}^{3}$ & 15.65 \\
\hline Mean particle size, $\mu \mathrm{m}$ & 1.07 \\
\hline Specific surface $($ BET $), \mathrm{m}^{2} / \mathrm{g}$ & 0.42 \\
\hline
\end{tabular}

Table 1. Characteristics of the WC powder.

Several WC10wt.\%Co mixtures containing up to 2 wt.\% of $\mathrm{La}_{2} \mathrm{O}_{3}$ and $\mathrm{CeO}_{2}$ of the cobalt phase were prepared (Table 2). The samples of dry powders were mixed and homogenized in a laboratory mixer during $1 \mathrm{~h}$. 


\begin{tabular}{|l|c|c|c|}
\hline \multirow{2}{*}{ Samples } & \multirow{2}{*}{ WC10wt.\%Co } & \multicolumn{2}{|c|}{ Rare-earth } \\
\cline { 3 - 4 } & & $\mathrm{La}_{2} \mathrm{O}_{3}$ & $\mathrm{CeO}_{2}$ \\
\hline AL1 & 100.0 & - & - \\
\hline AL2 & 99.5 & 0.5 & - \\
\hline AL3 & 99.0 & 1.0 & - \\
\hline AL4 & 98.5 & 1.5 & - \\
\hline AL5 & 98.0 & 2.0 & - \\
\hline AL6 & 99.5 & - & 0.5 \\
\hline AL7 & 99.0 & - & 1.0 \\
\hline AL8 & 98.5 & - & 1.5 \\
\hline AL9 & 98.0 & - & 2.0 \\
\hline
\end{tabular}

Table 2. Composition of the cemented carbides doped with rare-earths.

\subsection{High pressure sintering of the cemented carbide}

The mixed powders initially were submitted to a single action die-compaction step using a hydraulic press (Danpresse, model DC 20) in a cylindrical $7 \mathrm{~mm}$ diameter steel die without lubrificants at $800 \mathrm{MPa}$. The compact dimensions were $7 \mathrm{~mm}$ in diameter and $7 \mathrm{~mm}$ in height. After uniaxial compaction, the consolidated samples were pressed under high pressure and high temperature (HPHT).

The high pressure compaction needs an apparatus that can stably generate a pressure of more than $1 \mathrm{GPa}$. A toroidal type high-pressure device was used in the experiments. Fig. 1 shows a typical drawing of the high-pressure device (Ramalho, 1998). This device allows the compaction tests in cylindrical powder samples until $7 \mathrm{~mm}$ of diameter and $9 \mathrm{~mm}$ of height. The high-pressure tests were carried out in a special hydraulic press (Ryazantyashpressmash, DO 138B model). The tests were carried out as follows: the precompacted mixed powder sample was placed without slackness into central aperture of the deformable capsule (Fig. 1). The deformable capsule is made of a calcite based powder compact $\left(95 \% \mathrm{CaCO}_{3}+5 \%\left(\mathrm{SiO}_{2}, \mathrm{Al}_{2} \mathrm{O}_{3}, \mathrm{Fe}_{2} \mathrm{O}_{3}\right)\right)$. The calcite based material is a solid pressure medium well known in the field of ultrahigh pressure technology (Vianna et al., 2001). For effective heat conduction in the sample, the capsule was covered with two caps composed of $50 \%$ of graphite and $50 \%$ of calcite. A high pressure anvil made of hard metal was used as mould, where the capsule was fixed in its concavity, and then sealed with the outer side of the mould. Finally, the complete device was axially placed in the mobile table of the press. When the force is applied, the capsule is deformed with concomitant formation of a gasket and the generation of a high pressure. A high pressure of $5.5 \mathrm{GPa}$ was applied to the samples. The high pressure into the compression chamber was transmitted to the cemented carbide powder samples by the capsule. The high pressure level reached was maintained for $30 \mathrm{~s}$, and then the temperature was raised to $1400{ }^{\circ} \mathrm{C}$. These conditions of high pressure and high temperature were maintained for a time of $40 \mathrm{~s}$. 


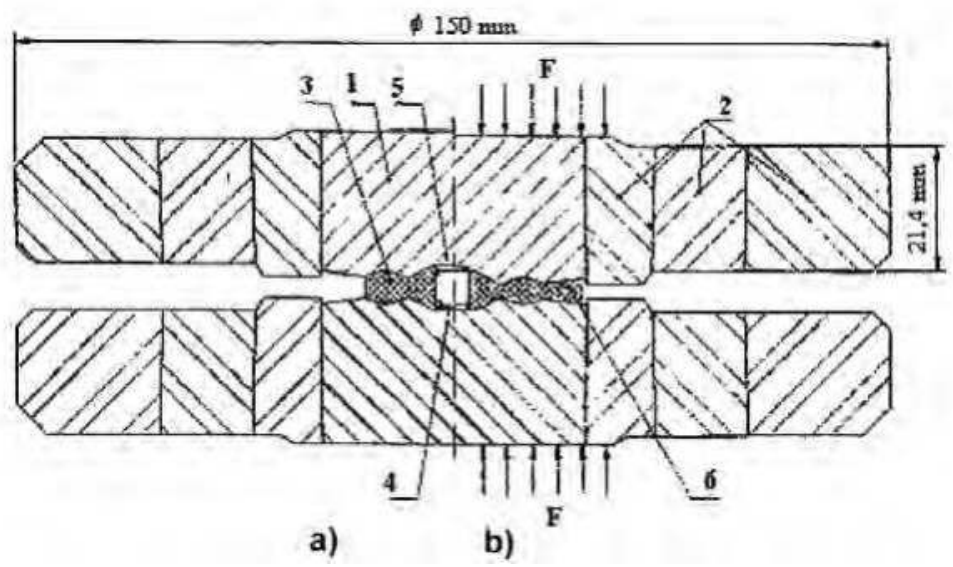

Fig. 1. Anvil type high pressure device with toroidal concavity for press of 630 tonnes:

a) the high pressure device without applying pressure; and b) the high pressure device with application of pressure. 1) Anvil of WC; 2) multi-rings; 3) deformable capsule; 4) sample of WC10wt.\%Co; 5) disk of protection; and 6) gasket (Ramalho, 1998).

\subsection{Characterization of the cemented carbide pellets}

After high pressure sintering, the cylindrical pellets $(6 \mathrm{~mm}$ in diameter and $4 \mathrm{~mm}$ in height) were removed from the capsule. The surface in contact with the graphite was clean and was later made a grinding surface resulting in parallel tops and cylindrical side.

For metallographic analysis, the sample was embedded in thermosetting polymer resin and then was made polishing in diamond paste. The metallographic analysis was made using an optical microscope (Zeiss, model Neophot-32) that contains an image capture system with CCD camera attached.

Scanning electron microscopy operating at $10 \mathrm{kV}$ (model SSX 550, Shimadzu) was used to examine the gold-coated fracture surfaces of the sintered cemented carbide pellets via secondary electron images (SEI). EDS also was used to identify the constituent elements of the sintered samples.

The crystalline phases after sintering were investigated between $2 \theta=20^{\circ}$ and $2 \theta=90^{\circ}$ via $X$ ray diffraction analysis (Shimadzu, model XRD 7000) with $\mathrm{Cu}-\mathrm{K} \alpha$ radiation $(40 \mathrm{kV}, 40 \mathrm{~mA})$. The phases were identified from peak positions and intensities using reference data from the JCPDS handbook.

The following properties have been determined: apparent density, relative density, coercive force, mechanical strength, elasticity modulus, microhardness, and wear resistance. Archimedes method of immersion in water was used to determine the apparent density. For this purpose, the cemented carbide pellets were weighed at dry state (M1), then boiled in water for $2 \mathrm{~h}$, cooled, and weighed again a second time in water (M2). The pellets were weighed again at the saturated wet state (M3). The apparent density $\left(\rho_{a}\right)$ of pellets was determined according to: 


$$
\rho_{\mathrm{a}}=\mathrm{M} 1 / \mathrm{M} 3-\mathrm{M} 2
$$

The relative density $\left(\rho_{\mathrm{r}}\right)$ was determined according to the following expression:

$$
\rho_{\mathrm{r}}=\rho_{\mathrm{a}} / \rho_{\mathrm{t}}
$$

in which $\rho_{a}$ is the apparent density $\left(\mathrm{g} / \mathrm{cm}^{3}\right)$ and $\rho_{\mathrm{t}}$ is the theoretical density of the WC10wt.\%Co $\left(14.53 \mathrm{~g} / \mathrm{cm}^{3}\right)$.

The coercive force of the pellets was determined using a coercive force meter, which create a magnetic field. The test of coercive force was performed as follow. Initially, the coercive force meter was reset. The pellets were placed in the polarized magnetization devices. It was then made to read the display of the coercive force.

In this work the mechanical strength of the pellets was evaluated through axial compression strength due to the size of the pellets obtained. This means that the values of mechanical strength of the samples obtained in this work are for comparison only among themselves. The axial compressive strength $\left(\sigma_{c}\right)$ was determined using an universal testing machine (EMIC, model DL - 10000) at a loading rate of $0.5 \mathrm{~mm} / \mathrm{min}$ according to

$$
\sigma_{\mathrm{c}}=4 \mathrm{P} / \pi \mathrm{D}^{2}
$$

in which $\mathrm{P}$ is the load at rupture and $\mathrm{D}$ the specimen diameter.

The axial compressive elasticity modulus $\left(\mathrm{E}_{\mathrm{CA}}\right)$ was determined using the stress-strain curve according to

$$
E_{C A}=\sigma_{A C} / \varepsilon
$$

in which $\sigma_{\mathrm{AC}}$ is the axial compressive tension and $\varepsilon$ is the relative deformation.

The Vickers microhardness tests were performed using a microhardness apparatus coupled to an optical microscope according to

$$
\mathrm{HV}=0.189 \mathrm{P} / \mathrm{d}^{2}
$$

in which $\mathrm{P}$ is the applied load (kgf) and $\mathrm{d}$ is the average length of the impression diagonal (mm).

The abrasion wear tests were performed using an abrasion meter (AROTEC, model AROPOL E) with maximum speed of $620 \mathrm{rpm}$ and disk of carborundun. The following procedure was adopted: i) the sample is weighed before the wear test; ii) the sample was fixed in a chuck property for the test; iii) the disk is rotated and applied a vertical load on the sample fixed; iv) the sample was kept fixed in a straight line for $10 \mathrm{~min}$; and v) the sample is weighed after the test for determining the mass loss. Thus, the wear resistance of the sintered pellets was determined according to

$$
\Delta \mathrm{M}=\mathrm{m}_{\mathrm{i}}-\mathrm{m}_{\mathrm{f}} / \mathrm{m}_{\mathrm{i}} \times 100
$$

in which $m_{i}$ is the initial mass $(\mathrm{g})$ of the pellets and $\mathrm{m}_{\mathrm{f}}$ is the final mass $(\mathrm{g})$ obtained after the wear test. 


\section{Results and discussion}

\subsection{Structural characterization}

XRD patterns of the WC10wt.\%Co samples are presented in Fig. 2. As expected, the results showed that at room temperature (Fig. 2a) the mixed powder is composed of the crystalline phases WC and Co. The low intensity of the peaks of cobalt may be related to $\mathrm{Cu}-\mathrm{K} \alpha$ radiation used. When the mixed powder is sintered under high pressure and high temperature (5.5 GPa and $1400^{\circ} \mathrm{C}$ ), as shown in Fig. 2b, characteristic peaks of WC, Co and $\mathrm{Co}_{3} \mathrm{~W}_{3} \mathrm{C}$ are identified. In addition, a small amount of the y phase was also identified.
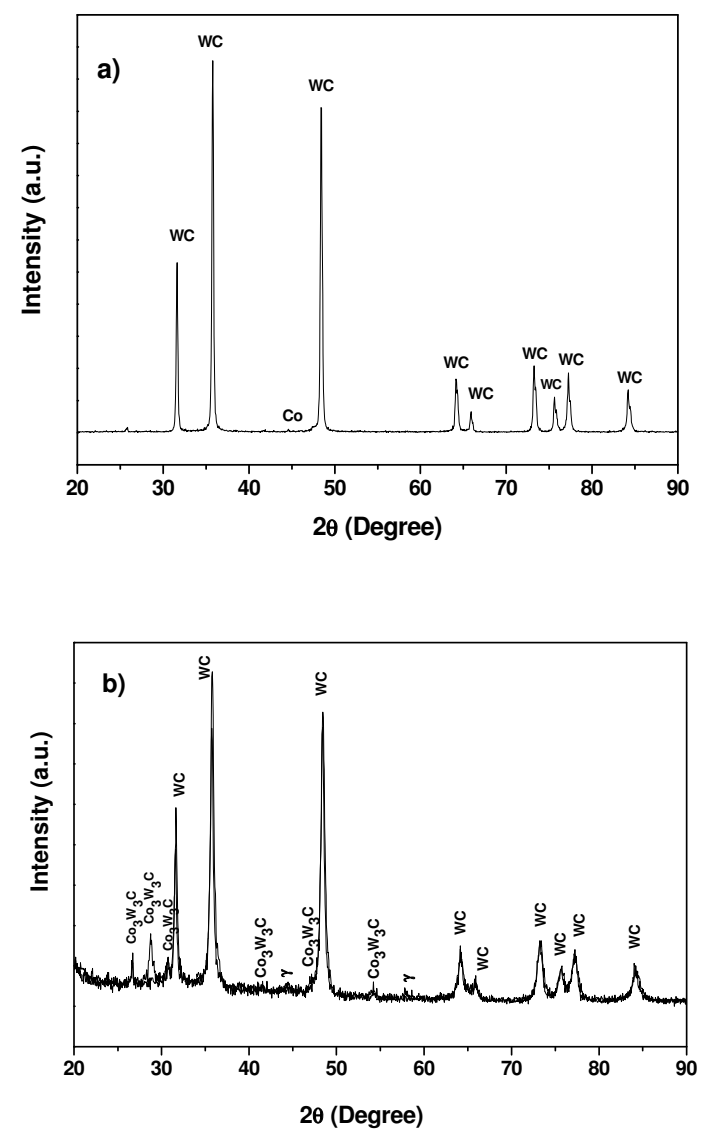

Fig. 2. XRD patterns of the WC10wt.\%Co: a) before sintering; and b) after sintering.

The XRD analysis showed the formation of intermediate phases such as $\mathrm{Co}_{3} \mathrm{~W}_{3} \mathrm{C}$ and $\mathrm{y}$. These phases formed are undesired because they are harmful to the mechanical properties of cemented carbide. The appearance of these phases during sintering is consistent with the binary diagram of WC-Co (Silva, 1996). It is possible that these phases can be related to the 
following factors: i) sensitivity of the WC to the loss of carbon as consequence of their low formation energy; ii) sintering atmosphere with characteristic oxidant; and iii) the presence in the starting powders of compounds that react with the carbide, consumining the carbon. Another important aspect that must be considered is that the HPHT sintering process is very fast. This can take the carbon to react with the adsorbed oxygen also quickly, resulting in decrease or loss of carbon of the WC. The consequence is not having a good dissolution of free carbon in the liquid phase, so new phases can occur by diffusion.

Figures 3 and 4 show the X-ray diffraction patterns of the cemented carbide samples doped com rare-earth elements.

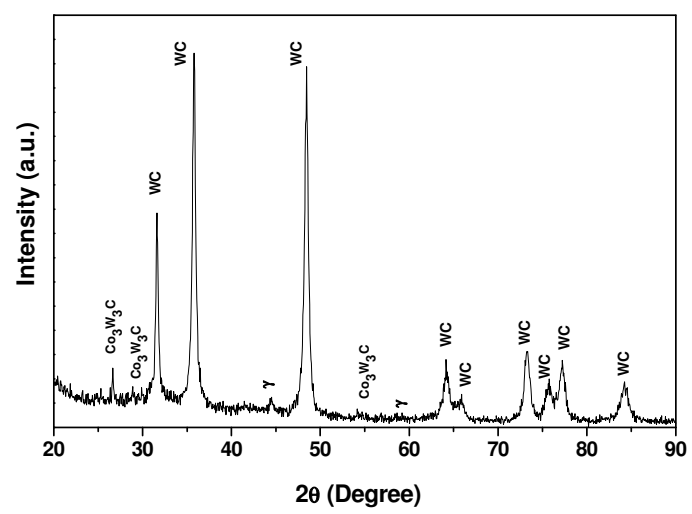

Fig. 3. XRD pattern of the WC10wt. \% Co doped with $2 \%$ of $\mathrm{La}_{2} \mathrm{O}_{3}$ sintered under HPHT.

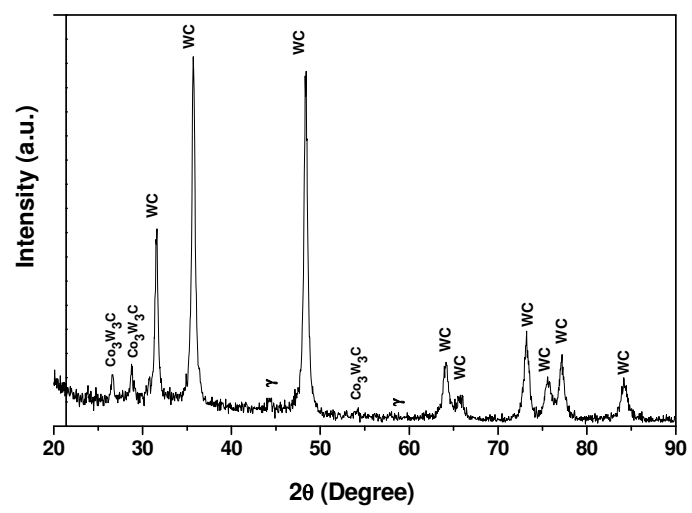

Fig. 4. XRD pattern of the WC10wt.\% Co doped with $2 \%$ of $\mathrm{CeO}_{2}$ sintered under HPHT.

As can be observed, the samples doped with rare-earth elements $\left(\mathrm{La}_{2} \mathrm{O}_{3}\right.$ (Fig. 3) and $\mathrm{CeO}_{2}$ (Fig. 4)) had a phase composition very similar to that of the rare-earth free samples. It is noticed that only small differences in the peak intensities occurred. This means that the 
formation of these intermediate phases is not associated with the rare-earth elements incorporated in the cemented carbide studied.

\subsection{Densification}

The apparent density of the pellets of WC10wt.\%Co doped with rare-earth elements sintered under HPHT is shown in Fig. 5. It can be observed that the samples containing rareearth elements showed higher apparent density. The highest values were obtained for samples containing $2 \% \mathrm{La}_{2} \mathrm{O}_{3}\left(14.00 \mathrm{~g} / \mathrm{cm}^{3}\right)$ and $0.5 \% \mathrm{CeO}_{2}\left(13.53 \mathrm{~g} / \mathrm{cm}^{3}\right)$.

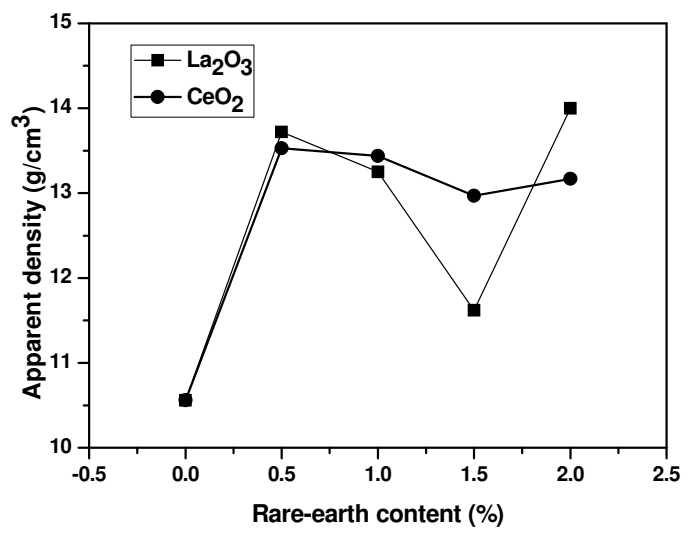

Fig. 5. Apparent density of the cemented carbides sintered under HPHT.

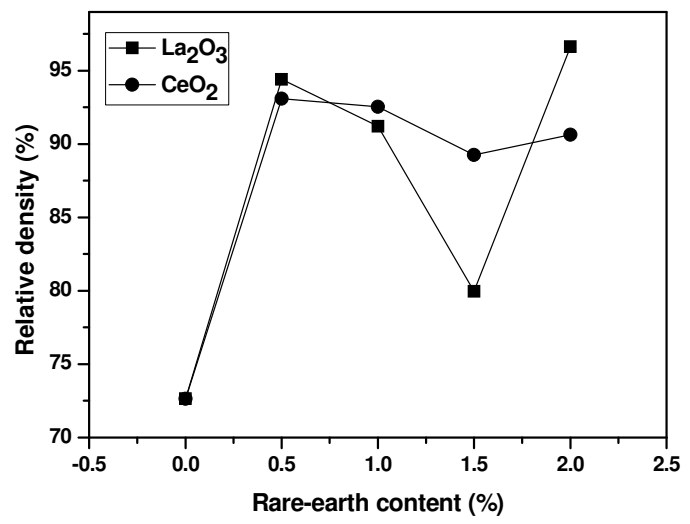

Fig. 6. Relative density of the cemented carbides sintered under HPHT.

The densification behavior of the cemented carbide as a function of the content of rare-earth elements is shown in Fig. 6. The value of theoretical density for the cemented carbide used (WC10wt.\%Co) was $14.54 \mathrm{~g} / \mathrm{cm} 3$. 
According to the literature (Arbilla et al., 1996), the manufacturing of cemented carbide (WC10wt.\% Co) is basically the liquid phase sintering of powder mixture of tungsten carbide and cobalt at a temperature of approximately $1400{ }^{\circ} \mathrm{C}$. At this temperature, the cobalt becomes liquid and diffuses into the structure and, after cooling, the desired properties are obtained. In this work, however, an unusual process was used for the production of cemented carbide doped with rare-earth elements.

The results in Fig. 5 indicated that the WC10wt.\%Co-free rare-earth elements showed a low value of apparent density $\left(10.56 \mathrm{~g} / \mathrm{cm}^{3}\right)$, reaching a densification of about $73 \%$ (Fig. 6). Whereas the samples studied were subjected to the HPHT process, it was expected a higher value. Furthermore, this value is lower than in the cemented carbide densification obtained in industrial routines (Gomes et al., 2004).

The sintering when performed via the HPHT process tends to promote greater adhesion between the particles and higher densification in the material. However, the actions of certain factors must be taken into account because they can lead to some variations such as (Rodrigues et al., 2006; Bobrovnitchii, 2001): i) the presence of gradients of temperature and pressure in the compression chamber of the DAP may result in residual stresses and cracks in the samples; and ii) the rapid reduction of pressure and temperature can cause defects in the samples.

It can also be seen in Figure 6 that the samples containing rare-earth element showed a high densification. In particular, the samples with higher degree of densification were those containing $2 \%$ of $\mathrm{La}_{2} \mathrm{O}_{3}(96.63 \%)$ and $0.5 \%$ of $\mathrm{CeO}_{2}(93.10 \%)$ in relation the cobalt phase. Importantly, all cemented carbide samples obtained had the same procedure of manufacture. This fact confirms that the rare-earth elements incorporated into the WC10wt.\%Co contribute effectively to the high densification of the pellets sintered under HPHT conditions. This result is consistent with the literature (Xu et al., 2001; Gomes, 2004).

According to the literature (Ji et al., 1996), the addition of rare-earth element leads to decreased porosity of the cemented carbide. As the cemented carbide is a fragile PM material, porosity always causes great tension, which is a source of fracture. There is a direct relationship between mechanical strength and porosity of the cemented carbide, in which fewer pores and smaller pore size results in higher mechanical strength. During the sintering cycle, gaseous impurities, for example, oxygen and sulfur in cemented carbide is partially released in gaseous form. If they are not partially removed such defects as pores will take shape. Since the form of sulfide and oxide compounds of rare earths, which are stable at high temperatures, gaseous impurities are reduced and thus reduce the possible formation of pores. However, reducing the temperature required for the liquid phase by the addition of rare-earth element implies that under the same conditions of sintering, the sintering time by liquid phase has been extended, which leads to significant displacement of material, filling of pores with the liquid phase and decrease in number and size of pores. This fact is combinated with the effect of high pressure and high temperature that promote the filling of empty spaces by the binder metal.

\subsection{Coercive force}

Figures 7 and 8 present the values of coercive force $(\mathrm{Hc})$ of the cemented carbide produced via HPHT as a function of the rare-earth elements added. The results show that the addition of rare-earth elements in the structure of the cemented carbide influences the coercive field. 
This magnetic property is very sensitive to microstructure and chemical composition of the cemented carbide.

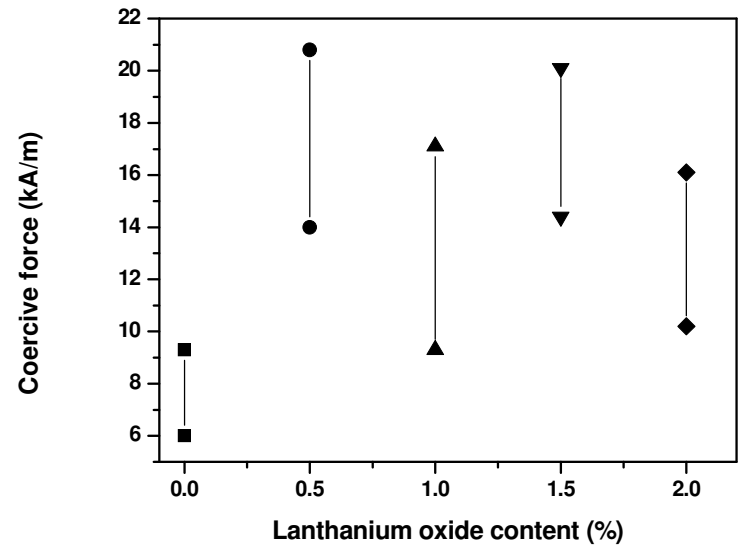

Fig. 7. Coercive force of the cemented carbides doped with lanthanum oxide sintered under HPHT.

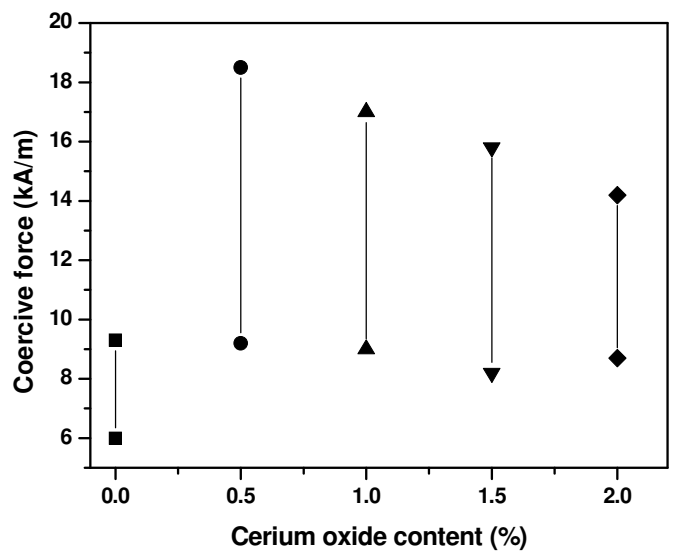

Fig. 8. Coercive force of the cemented carbides doped with cerium oxide sintered under HPHT.

As observed in Figs 7 and 8 there is variability in the values obtained for the coercive force. However, this variability is also observed in the literature (Brookes, 1998) for the cemented carbide. The coercive force values obtained in this work are also within the range of Hc for the cemented carbide (WC10wt.\%Co). 
The measures of coercive force of the sintered pellets indicated an increase in the coercive field of the WC10wt.\%Co doped with rare-earth elements. This increase in the coercive field may have been influenced by the WC grain size resulting from the refinement of the microstructure caused by the rare-earth elements. It is reported in the literature (Xu et al., 2001) that these elements inhibit the grain growth of WC thereby making thinner. The values of Hc increase with the refinement of microstructure, because this makes it difficult to magnetization of the material in the direction of the applied field. Thus, it is necessary to generate higher coercive force to magnetize the WC10wt.\%Co. The high value of Hc indicates that the cemented carbide studied corresponded to the class of magnetically hard materials, the application it is intended for light machining. The results also showed that the lanthanum oxide $\left(\mathrm{La}_{2} \mathrm{O}_{3}\right)$ was the most effective in increasing the coercive field of the WC10wt.\%Co. The sample with $0.5 \%$ of lanthanum oxide reached the highest value of Hc $(14.0-20.8 \mathrm{kA} / \mathrm{m})$. In the case of addition of cerium oxide $\left(\mathrm{CeO}_{2}\right)$, the sample with $0.5 \%$ of $\mathrm{CeO}_{2}$ reached the highest value of $\mathrm{Hc}(9.2-18.5 \mathrm{kA} / \mathrm{m})$.

\subsection{Axial compressive strength}

The behavior of the axial compressive strength as a function of the rare-earth content of the pellets of cemented carbides sintered under HPHT is shown in Fig. 9.

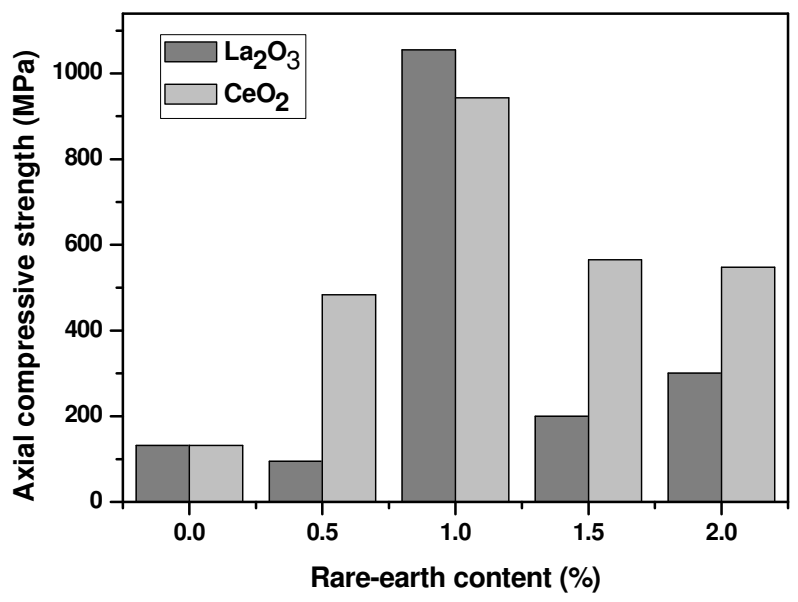

Fig. 9. Axial compressive strength of the cemented carbides sintered under HPHT.

The effect of the addition of rare-earth elements was to increase the compressive strength of the pieces of WC10wt.\%Co. This is mainly associated with increased densification of the cemented carbide containing rare-earth during the sintering process. In addition, the rareearth additive can inhibit the martensitic phase transformation of Co phase $(\varepsilon-\mathrm{Co})$, which weakens the material resulting in the increase of $\alpha$-Co (CFC) that contributes directly to increased mechanical strength (Xu et al., 2001).

The results of Figure 9 also showed different behavior for the axial compressive strength, depending on the rare-earth added. The highest values of mechanical strength of the 
cemented carbide doped with rare-earth elements were obtained for the samples containing $1 \%$ of $\mathrm{La}_{2} \mathrm{O}_{3}(1055 \mathrm{MPa})$ and $1 \%$ of $\mathrm{CeO}_{2}(943 \mathrm{MPa})$. In addition, the complex variation observed for the mechanical strength may be associated with the fact that some samples did not show regular cylinder geometry (Fig. 10).

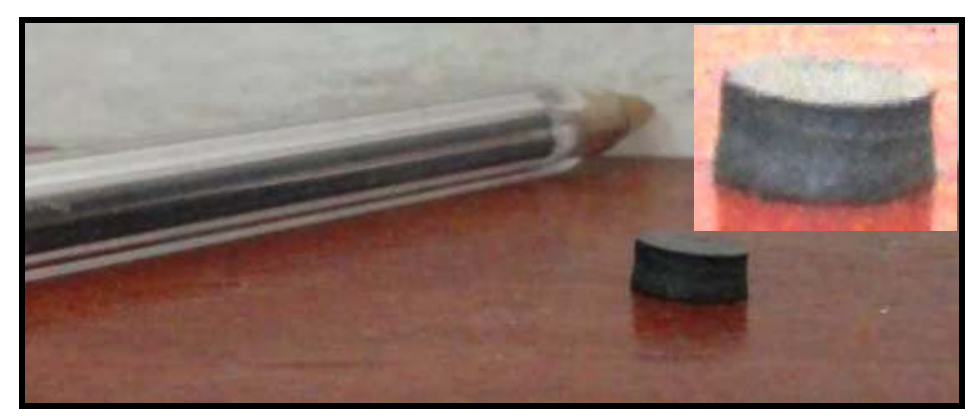

Fig. 10. Appearance of the pellets of WC10wt.\% Co obtained via HPHT.

\subsection{Axial compressive elasticity modulus}

The axial compressive elasticity modulus of the cemented carbides obtained from the tension-deformation curve resulting from axial compression tests is shown in Fig. 11.

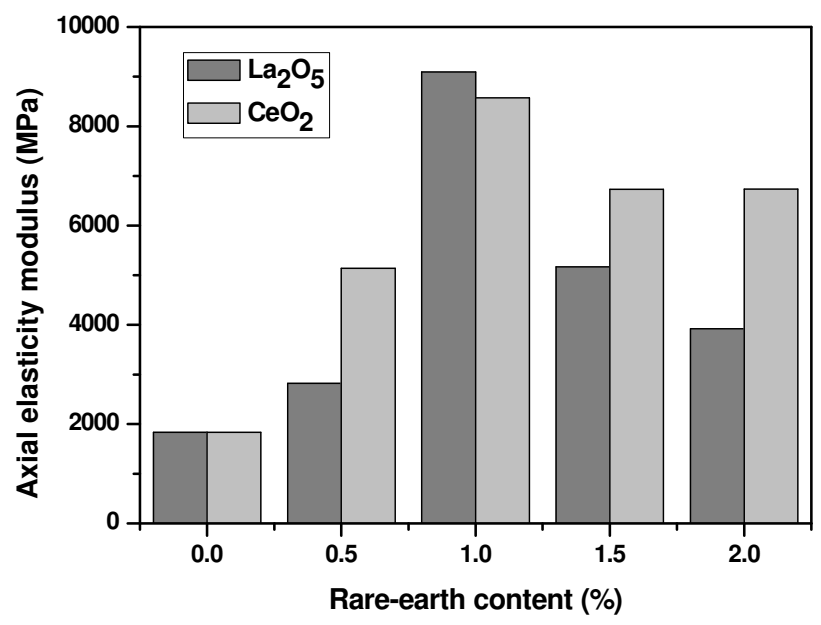

Fig. 11. Axial elasticity modulus of the cemented carbides sintered under HPHT.

The cemented carbides are characterized by a high modulus of elasticity. In a way similar to the axial compressive strength, it is observed that the axial compressive elasticity modulus increased with the incorporation of rare-earth oxides. This is mainly due to higher densification of the cemented carbide doped with these additives. 
The results of Figure 11 also showed that the highest values of axial compressive elasticity modulus of the cemented carbide doped with rare-earth elements were obtained for the samples containing $1 \%$ of $\mathrm{La}_{2} \mathrm{O}_{3}(9095 \mathrm{MPa})$ and $1 \%$ of $\mathrm{CeO}_{2}(8573 \mathrm{MPa})$.

\subsection{Microhardenss}

Figure 12 shows the values of microhardness for the pellets of WC10wt.\%Co doped with rare-earth elements. The results show that the microhardness increases with the addition of rare-earth elements. This increase may be due to increased densification with the rare earth added. On the other hand, the complex variation in microhardness values may have been influenced by the geometric irregularity at the top and bottom of the samples caused by the sintering process as previously described.

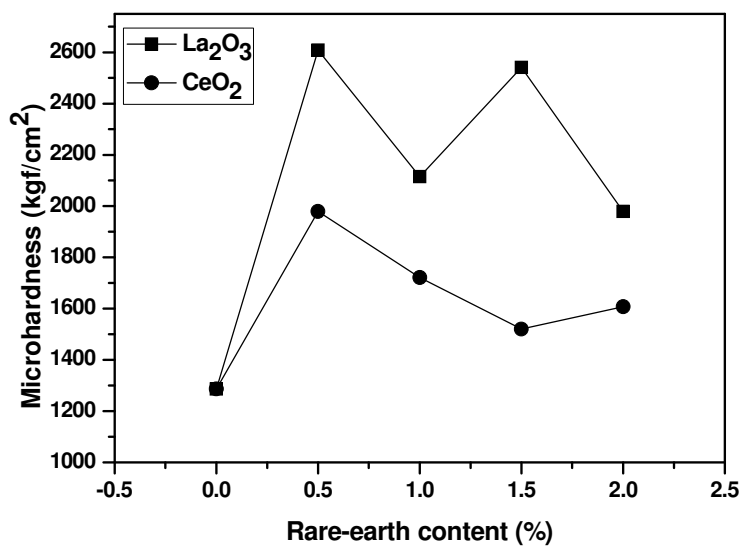

Fig. 12. Microhardness of the cemented carbides sintered under HPHT.

It can be seen in Fig. 12 an increase in microhardness when $0.5 \%$ of $\mathrm{La}_{2} \mathrm{O}_{3}$ is added. A decrease in microhardness occurs with the addition of $1 \%$ of $\mathrm{La}_{2} \mathrm{O}_{3}$. With the addition of 1.5 $\%$ of $\mathrm{La}_{2} \mathrm{O}_{3}$, the microhardness increases again and back to decrease with $2 \%$ of $\mathrm{La}_{2} \mathrm{O}_{3}$. For cemented carbide containing cerium oxide, there is an increase with the addition of $0.5 \%$ and a subsequent decrease between 1 to $1.5 \%$. An increase occurs again with the addition of $2 \%$ of $\mathrm{CeO}_{2}$. It can also be observed that the highest values of microhardness of the cemented carbide doped with rare-earth elements were obtained for the samples containing $0.5 \%$ of $\mathrm{La}_{2} \mathrm{O}_{3}(2609 \mathrm{HV})$ and $0.5 \%$ of $\mathrm{CeO}_{2}(1979 \mathrm{HV})$.

\subsection{Wear resistance}

Table 3 presents the values of wear resistance for the pellets of cemented carbide doped with rare-earth elements obtained under HPHT conditions. The results indicated that all samples of cemented carbide containing rare-earth elements showed less mass loss compared to the reference sample (WC10wt.\%Co). This was expected, since the decrease in grain size caused by the rare-earth elements and also the positive influence of high pressure leads to increased microhardness and, consequently, to reduce the wear. 


\begin{tabular}{|l|c|}
\hline Samples & Wear resistance (\%) \\
\hline AL1 & 7.7 \\
\hline AL2 & 3.7 \\
\hline AL3 & 0.2 \\
\hline AL4 & 0.1 \\
\hline AL5 & 0.1 \\
\hline AL6 & 0.1 \\
\hline AL7 & 1.7 \\
\hline AL8 & 0.2 \\
\hline AL9 & 0.3 \\
\hline
\end{tabular}

Table 3. Wear resistance of the cemented carbides sintered under HPHT.

The results in Table 3 also show that the best samples in terms of wear resistance are those with 1.0 to $2.0 \%$ of $\mathrm{La}_{2} \mathrm{O}_{3}$ and $0.5,1.5$ and $2.0 \%$ of $\mathrm{CeO}_{2}$.

\subsection{Microstructural analysis}

Optical micrograph of the sample of WC10wt.\%Co free of rare-earth sintered under HPHT is shown in Fig. 13. One can observe a non-homogeneous distribution of WC by the structure, indicating a possible change of the sintering conditions. On the other hand, there is a good distribution of cobalt for samples containing rare-earth elements (Figs. 14 e 15). This means better mixing or influence of the rare-earth about the process.

SEM micrographs of the fractured surfaces of the samples of WC10wt.\%Co with and without rare-earth additives are presented in Figs. 16 - 18. It may be noted that the appearance of the fractured surface is typical of brittle fracture for all samples.

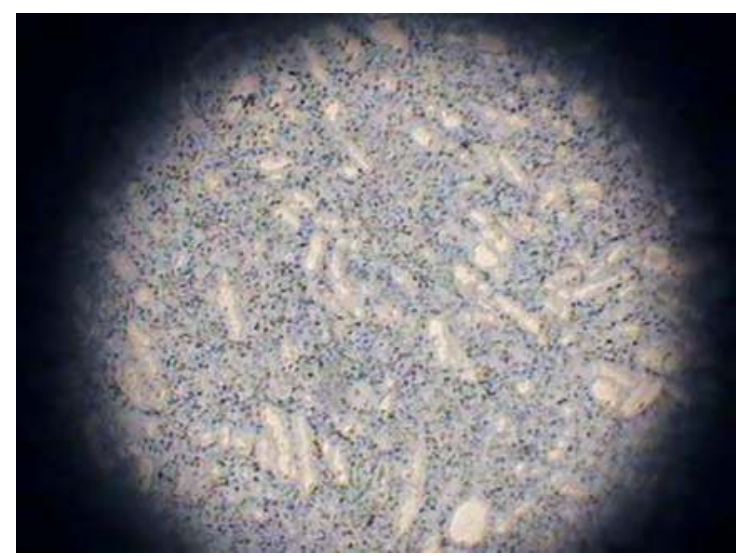

Fig. 13. Optical micrograph of the AL1 sample sintered under HPHT. 


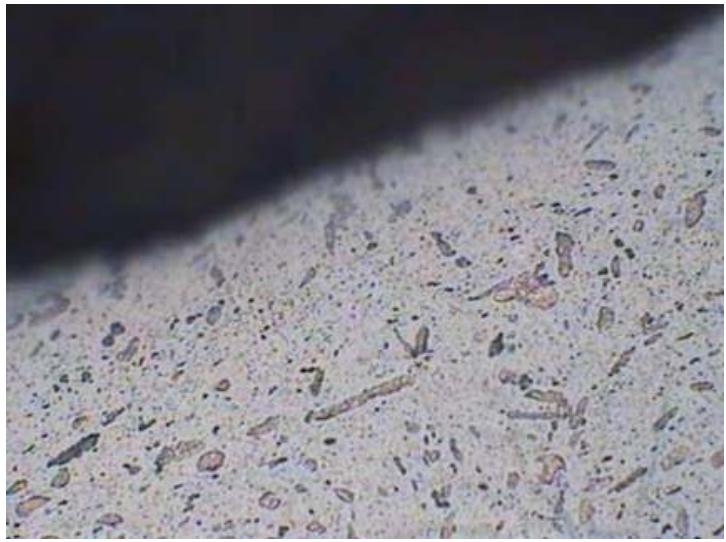

Fig. 14. Optical micrograph of the AL5 sample sintered under HPHT.

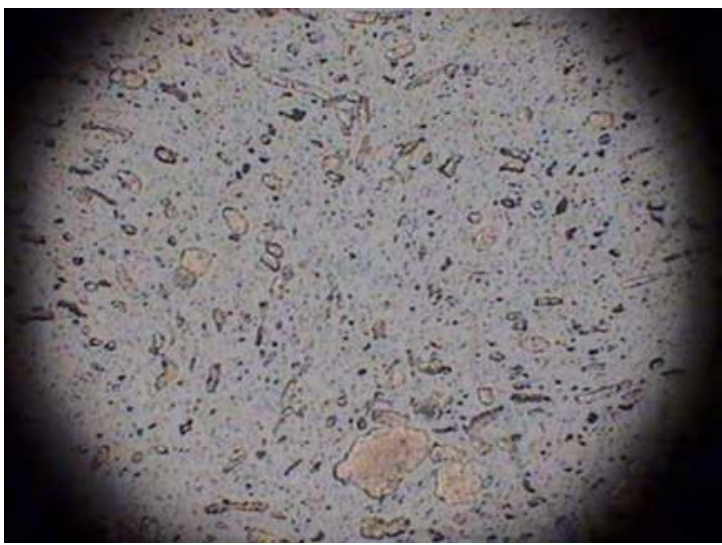

Fig. 15. Optical micrograph of the AL6 sample sintered under HPHT.

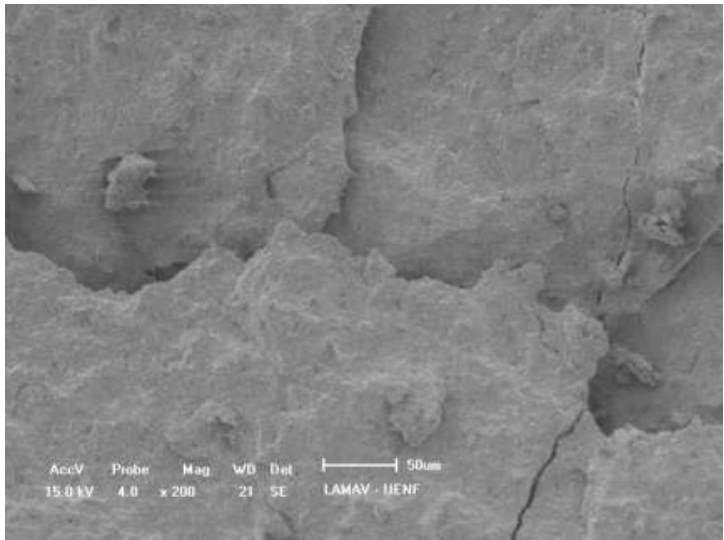

Fig. 16. Fracture surface of the of the AL1 sample sintered under HPHT. 


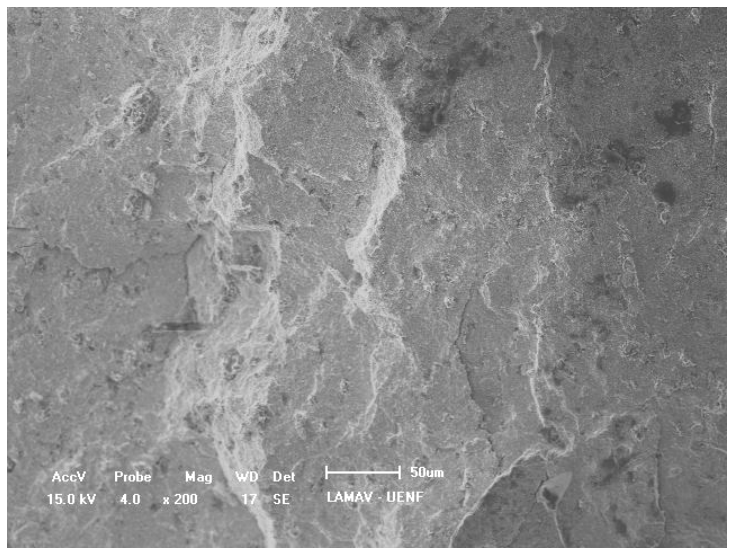

Fig. 17. Fracture surface of the of the AL5 sample sintered under HPHT.

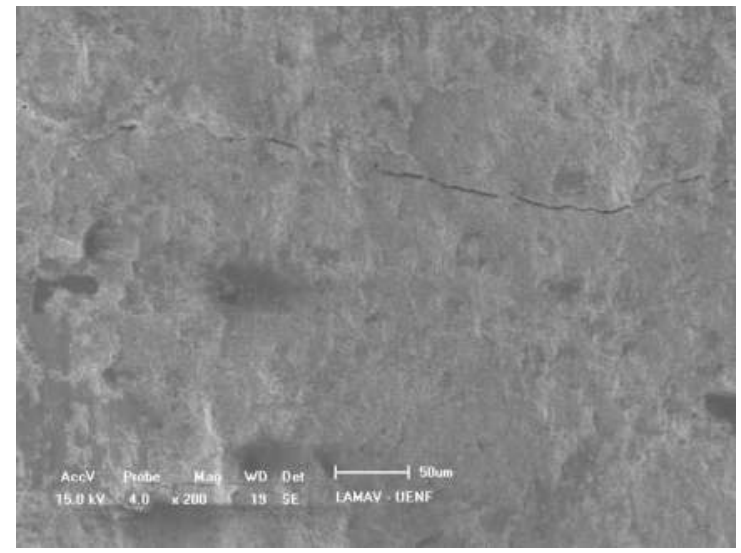

Fig. 18. Fracture surface of the of the AL7 sample sintered under HPHT.

Line spectrums for the samples of cemented carbides determined using EDS are shown in Figs. 19-21. The following constituent elements of the cemented carbides sintered under HPHT were detected: W, C, Co, La, and Ce.

The sintered microstructures of the AL5 $\left(2 \% \mathrm{La}_{2} \mathrm{O}_{3}\right)$ and AL7 $\left(1 \% \mathrm{CeO}_{2}\right)$ samples obtained via SEI/SEM are shown in Figs. 22-23, respectively. One can clearly observe the formation of cobalt lakes surrounding the tungsten carbide grains and pore possible. This may be related to different factors: i) mixing process inefficient; and ii) HPHT processing. According to North et al. (1992), high pressure applied continuously during the heating cycle can provide in some regions the formation of cobalt lakes, which persist at high temperatures even with some structural rearrangement of the WC. 


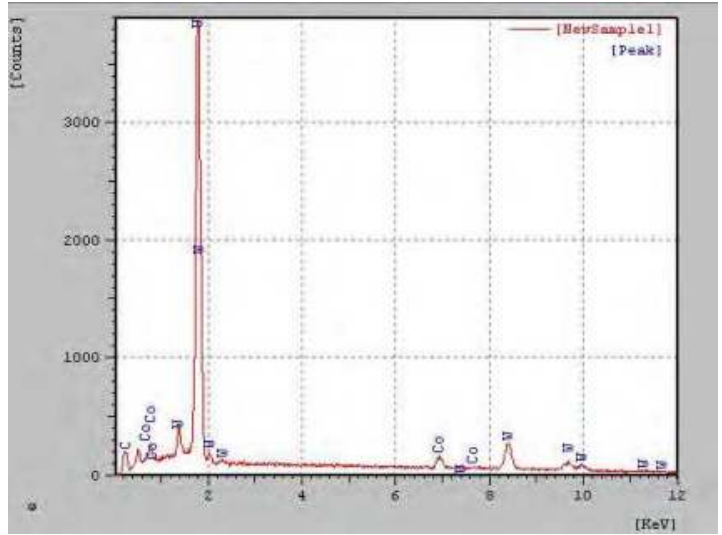

Fig. 19. EDS spectrum for the AL1 sample sintered under HPHT.

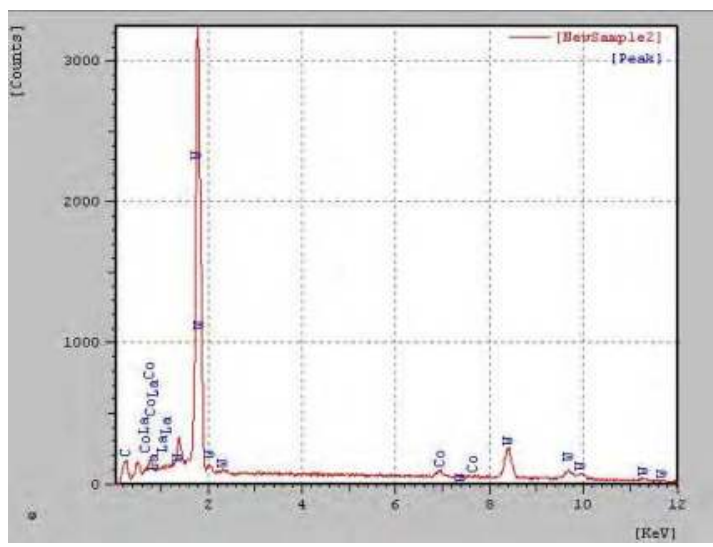

Fig. 20. EDS spectrum for the AL2 sample sintered under HPHT.

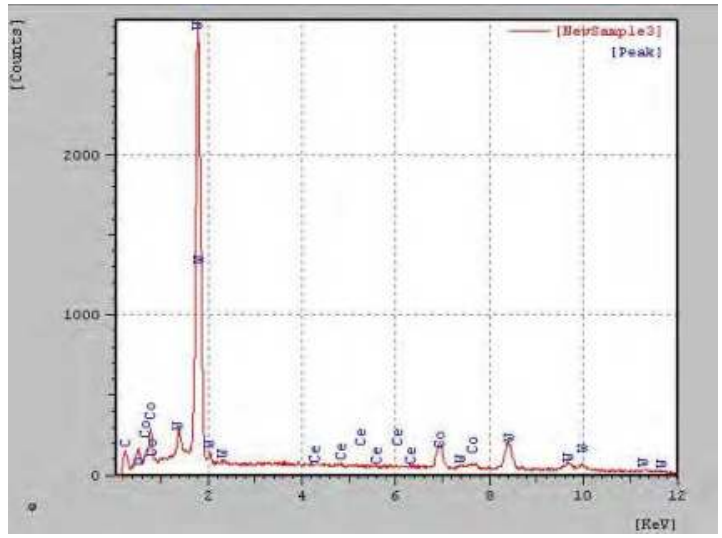

Fig. 21. EDS spectrum for the AL7 sample sintered under HPHT. 


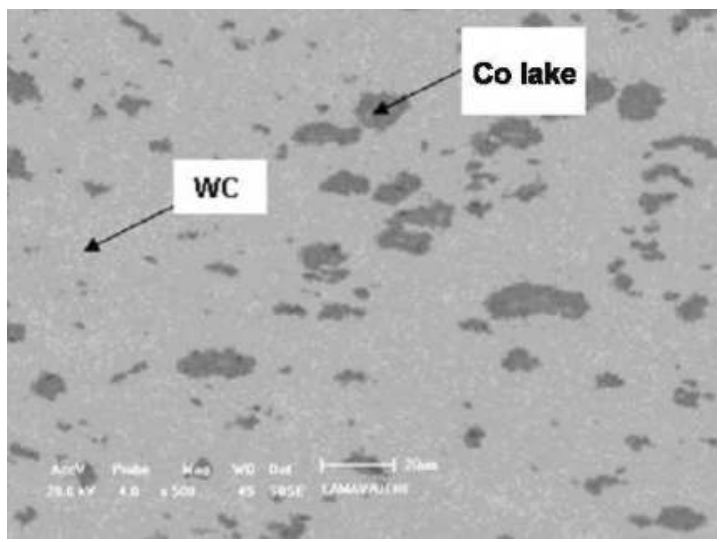

Fig. 22. SEM micrograph of the AL5 sample sintered under HPHT.

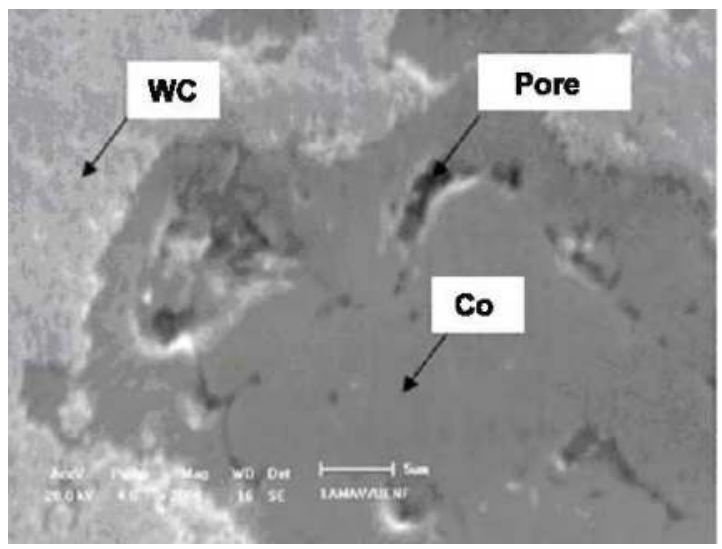

Fig. 23. SEM micrograph of the AL7 sample sintered under HPHT.

\section{Conclusion}

In this chapter the cemented carbide (WC10wt.\%Co) powder doped with different rare-earth elements $\left(\mathrm{La}_{2} \mathrm{O}_{3}\right.$ and $\left.\mathrm{CeO}_{2}\right)$ sintered under HPHT conditions was investigated. The method used can be an alternative for WC10wt.\% Co dense pellets processing. High final densities near theoretical density have been obtained. It was also found that the incorporation of rare-earth elements positively influenced the physical and mechanical properties of the cemented carbide. These properties include increased densification, increase in coercive field, axial compressive strength, axial elasticity, microhardness and wear resistance. This behavior is due to the addition of rare-earth elements leads to decreased porosity of the cemented carbide. Moreover, it was observed that the lanthanum oxide $\left(\mathrm{La}_{2} \mathrm{O}_{3}\right)$ was more effective in improving the properties of the cemented carbide investigated. 


\section{Acknowledgements}

The authors acknowledge the FAPERJ and CNPq for supporting this work.

\section{References}

Arbilla, G.; Corrêa, S.M. \& Carvalho, M.S. (1996). Ciência Hoje, Vol. 21,No. 122

Bobrovnitchii, G.S. (2001). Tendências do Desenvolvimento das Tecnologias de produção dos Materiais Superduros no Brasil, Proceedings of the 56th ABM Congress, Belo Horizonte, Brazil

Brooks, A.J.K. (1998). Hard Metals and Hard Materials, Third Ediiton, East Barnet Hertfordshire, United Kingdom

Cheng, J. \& Yu, Q. (1995). Wear Resistance of Rare-Earth Cemented Carbide Tools, Mech Eng, Vol. 4, pp. 9-10.

Chenguang, L. (1992). Composition Morphology and Distribution of RE Element Containing Phases in Cemented Carbide, International Journal of Refractory Metals and Hard Materials, Vol. 11, pp. 295-302

Deng, Q. (1993). Progress in the Study on Strengthening Mechanisms of Rare-Earth Cemented Carbide, Rare Metals, Vol. 17, pp. 442-454

German, R.M. (1994). Powder Metallurgy Science, MPIF, 2nd Edition, New Jersey, USA

Gomes, C.M.F. (2004). Estudo da Influência da Adição de Terras-Raras na Sinterização e Propriedades Mecânicas de Carbeto Cementado, Master Thesis, UENF, Campos dos Goytacazes, Brazil

He, C. (1996). Study on the Cutting Behavior of Rare-Earth Cemented Carbide, Cemented Carbide, Vol. 13, pp. 23-26

He, C.; Wang, Y. \& Ma, F. (1994). The Researching of Application of Hard Metal by Adding RE Element Cemented Carbide, Cemented Carbide, Vol. 11, pp. 129-133

Ji, X.; Jiang-gao, Y. \& Xing-hua, G. (1996). Application of Rare-Earth Elements in Cemented Carbide Inserts, Drawing Dies and Mining Tools, Materials Science and Engineering A, Vol. 209, pp. 287-293

Li, B. (1996). Effects of Adding Method of Rare-Earth on the Physical and Mechanical Properties and Performances of Cemented Carbide, Cemented Carbide, Vol. 13, pp. 15-18

Li, G.; Yan, L. \& Li, Z. (1986). Applications of Rare Earth Elements in Cemented Carbide, Powder Metallurgy Technology, Vol. 4, pp. 25-29

Li,G.; Yan, L.; Zhang, H. \& Li, F. (1994). Research on Rare-Earth Cemented Carbide YG6R, Powder Metallurgy Technology, Vol. 12, pp. 206-209

Li, G.; Yan, L. \& Zou, H. (1993). Distribution and Existent Morphology of Rare-Earths in Cemented Carbide, Powder Metallurgy Technology, Vol. 11, pp. 83-89

Liang, P.; Su, H. \& Jiang, N. (1989). Development of Cemented Carbide with Rare-Earth Elements, Cemented Carbide, Vol. 6, pp. 31-36

Liu, N.; Hu, Z. \& Kui, K. (1992). The Microstructure, Mechanical Properties and Development of Cemented Carbide with Rare-Earth Elements, Cemented Carbide, Vol. 10, pp. 50-53

Luo, Z. (1991). Research on the Effect of Rare-Earth Elements on the Properties of Cemented Carbide, Cemented Carbide, Vol. 8, pp. 12-19 
North, B.; Greenfield, M.S.; McCoy, W.C. \& Vankirk, J.S. (1992). Effect of Pressure Sinter and Post-Treatment on the Strength of Cemented Carbides, Advances in Powder Metallurgy and Particulate Materials, Vol. 8, pp. 111-123

North, B.; Pfouts, W.R. \& Greenfield, M.S. (1991). Pressure Sinter and HIP on Cemented Crabides, Metal Powder Report, pp. 40-45

Pan, Q. (1993). Effects of Rare-Earth Oxide on the Properties of WC-Co Cemented Carbide, Rare Met Mater Eng, Vol. 22, pp. 35-38

Ramalho, A.M. (1998). A Influência da Construção e dos Materiais sobre o Estado de Tensões do Cintamento dos Dispositivos de Alta Pressão do Tipo Bigorna Usados Na Produção de Materiais Superduros, Master Thesis, UENF, Campos dos Goytacazes, Brazil

Rodrigues, M.F.; Bobrovnitchii, G.S.; Quintanilha, R.; Cândido, R.; Silva, G. \& Figueira, M. (2006). Sinterização da Liga WC/10Co por Altas Pressões, Revista Matéria, Vol. 11, No. 3, pp. 174-180

Schwarzkopf, P. \& Kieffer, R. (1986). Cemented Carbides, MacMillan, New York, USA

Shan, S. (1990). Review of the Effect of Rare-Earth Element on the Cemented Carbides, Rare Met Cemented Carbide, Vol. 4, pp. 39-42

Silva, A.G.P. (1996). Study on Sintering and Grain Growth of WC-Based Hard Metals, Dissertation, Technischen Universität Wien, Wien, Austria

Thümmler, F. \& Oberacker, R. (1993). Introduction to Powder Metallurgy, The Institute of Materials, Cambridge, Great Britain

White, C. (1998). History of Powder Metallurgy, In: Handbook of Powder Metal Technologies and Applications, APMI, New York, USA

Willians, B. (1998). The History of Hard Metal, World Tooling, No. 3, pp. 4-7

Vianna, W.S.; Bobrovnitchii, G.S. \& Monteiro, S.N. (2001). Study of the Variation of the Electric Current During the Synthesis of Diamond Powders, Journal of Super Hard Materials, Vol. 5, No. 133, pp. 9-13

Xu, C.; Ai, X. \& Huang, C. (2001). Research and Development of Rare-Earth Cemented Carbides, International Journal of Refractory Metals and Hard Materials, Vol. 19, pp. 159-168

Yan, K.; Meng, T. \& Yu, J. (1995). The Effect on the Mechanical Properties and Cutting Performances of Cemented Inserted with Rare-Earth Metal Elements, Journal of the Southwest Jiaotong University, Vol. 30, pp. 46-51

Yang, J.; Xiong, J. \& Liu, J. (1993). Overview on the Present Research Situation of Cemented Carbide with Rare-Earths, Cemented Carbide, Vol. 10, pp. 46-49

Yao, X.; Huang, P. \& Lu, H. (1987). Effects of Rare-Earth Oxide on the Martensitic Transformation of Cobalt and Mechanical Properties of Cemented Carbide, Powder Metallurgy Technology, Vol. 5, pp. 200-204

Yuan, Y.; Bai, Y. \& Feng, H. (1995). Microstructure and Properties of the Cemented Crabide with Rare-Earth Element, Powder Metallurgy Technology, Vol. 13, pp. 88-91 


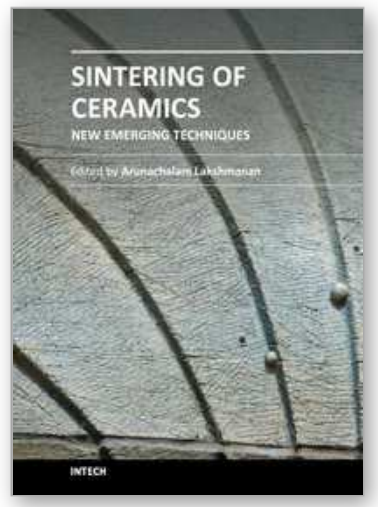

\author{
Sintering of Ceramics - New Emerging Techniques \\ Edited by Dr. Arunachalam Lakshmanan
}

ISBN 978-953-51-0017-1

Hard cover, 610 pages

Publisher InTech

Published online 02, March, 2012

Published in print edition March, 2012

The chapters covered in this book include emerging new techniques on sintering. Major experts in this field contributed to this book and presented their research. Topics covered in this publication include Spark plasma sintering, Magnetic Pulsed compaction, Low Temperature Co-fired Ceramic technology for the preparation of 3-dimesinal circuits, Microwave sintering of thermistor ceramics, Synthesis of Bio-compatible ceramics, Sintering of Rare Earth Doped Bismuth Titanate Ceramics prepared by Soft Combustion, nanostructured ceramics, alternative solid-state reaction routes yielding densified bulk ceramics and nanopowders, Sintering of intermetallic superconductors such as MgB2, impurity doping in luminescence phosphors synthesized using soft techniques, etc. Other advanced sintering techniques such as radiation thermal sintering for the manufacture of thin film solid oxide fuel cells are also described.

\title{
How to reference
}

In order to correctly reference this scholarly work, feel free to copy and paste the following:

C.M.F.G. Marques, G.S. Bobrovnitchii and J.N.F Holanda (2012). High Pressure Sintering of WC-10Co Doped with Rare-Earth Elements, Sintering of Ceramics - New Emerging Techniques, Dr. Arunachalam Lakshmanan (Ed.), ISBN: 978-953-51-0017-1, InTech, Available from: http://www.intechopen.com/books/sintering-ofceramics-new-emerging-techniques/high-pressure-sintering-of-wc-10co-doped-with-rare-earth-elements-

\section{INTECH}

open science | open minds

\author{
InTech Europe \\ University Campus STeP Ri \\ Slavka Krautzeka 83/A \\ 51000 Rijeka, Croatia \\ Phone: +385 (51) 770447 \\ Fax: +385 (51) 686166 \\ www.intechopen.com
}

\author{
InTech China \\ Unit 405, Office Block, Hotel Equatorial Shanghai \\ No.65, Yan An Road (West), Shanghai, 200040, China \\ 中国上海市延安西路65号上海国际贵都大饭店办公楼405单元 \\ Phone: +86-21-62489820 \\ Fax: +86-21-62489821
}


(C) 2012 The Author(s). Licensee IntechOpen. This is an open access article distributed under the terms of the Creative Commons Attribution 3.0 License, which permits unrestricted use, distribution, and reproduction in any medium, provided the original work is properly cited. 